\title{
Environmentally driven predator-prey overlaps determine the aggregate diet of the cod Gadus morhua in the Baltic Sea
}

\author{
Stefan Neuenfeldt" ${ }^{*}$ Jan E. Beyer \\ Danish Institute for Fisheries Research, Charlottenlund Castle, 2920 Charlottenlund, Denmark
}

\begin{abstract}
Aquatic ecosystems are environmentally heterogeneous with features such as fronts or clines of temperature and salinity. This heterogeneity varies over time and is likely to cause changes in predator-prey overlaps, which will affect the diet composition of the predators. We investigated how inflows of oxygenated and saline deep water alternating with stagnation periods affect the consumption rates of the herring Clupea harengus L. and the sprat Sprattus sprattus L. by the cod Gadus morhua in the Bornholm basin of the Baltic Sea. We developed conceptual models for the effect of predator-prey overlaps on the aggregate diet of the predator population to test the hypothesis that the effects of inflows on the aggregate diet are mediated by changes in cod-clupeid overlaps. After estimating salinity and oxygen thresholds of the spatial distributions of cod and clupeids and calculating cod-clupeid overlaps from March 1958 to 2004, we applied the models relating cod-clupeid overlaps to observed numbers and masses of herring and sprat in cod stomachs. Our study indicated that (1) the ratio of consumed herring to sprat increases faster than proportionally to the ratio of cod-herring to cod-sprat overlaps, and (2) the ratio of consumed herring to sprat increases slower than proportionally to the ratio of herring to sprat in the sea. The latter is most pronounced at the low ratios of overlaps that occur during stagnation periods, which destabilise the clupeid populations, and may have contributed to the drastic increase in the sprat abundance during the late 1980s.
\end{abstract}

KEY WORDS: Predator-prey overlap - Salinity threshold · Oxygen threshold · Aggregate diet · Apparent negative switching $\cdot$ Atlantic cod $\cdot$ Baltic Sea

\section{INTRODUCTION}

The effect of prey densities on the abundance of a prey species in the diet of an individual predator is expressed by the functional response (Holling 1959, Murdoch 1973). However, the aggregate diet of the entire predator population may not be predicted solely from the functional response of the individuals making up the population (Chesson 1984). This is because aquatic ecosystems are environmentally heterogeneous with features such as fronts or clines of temperature and salinity, which often serve to structure predator and prey populations in space. The heterogeneity varies over time due to different kinds of forcing such as surface warming in summer and winter storms. In such heterogeneous environments it is likely that prey habitats do not overlap fully with the predator habitat and that, hence, the prey-specific densities encountered by an individual predator depend on its location. Our aim was to investigate how environmentally driven predator-prey overlaps affect the aggregate diet of the predator population in a 1-predator to 2-prey system.

Our case study area, the Bornholm basin (Fig. 1), is situated in the Baltic Sea, which is among the largest brackish water areas of the world. The central Baltic consists of several deep basins, all of which show a pronounced vertical stratification of the water column. A permanent halocline at 50 to $75 \mathrm{~m}$ separates lowsalinity (ca. 7 psu) surface water from more saline (ca. 18 psu) deep water. Deep water is renewed by inflows of North Sea water, which are driven by initial 


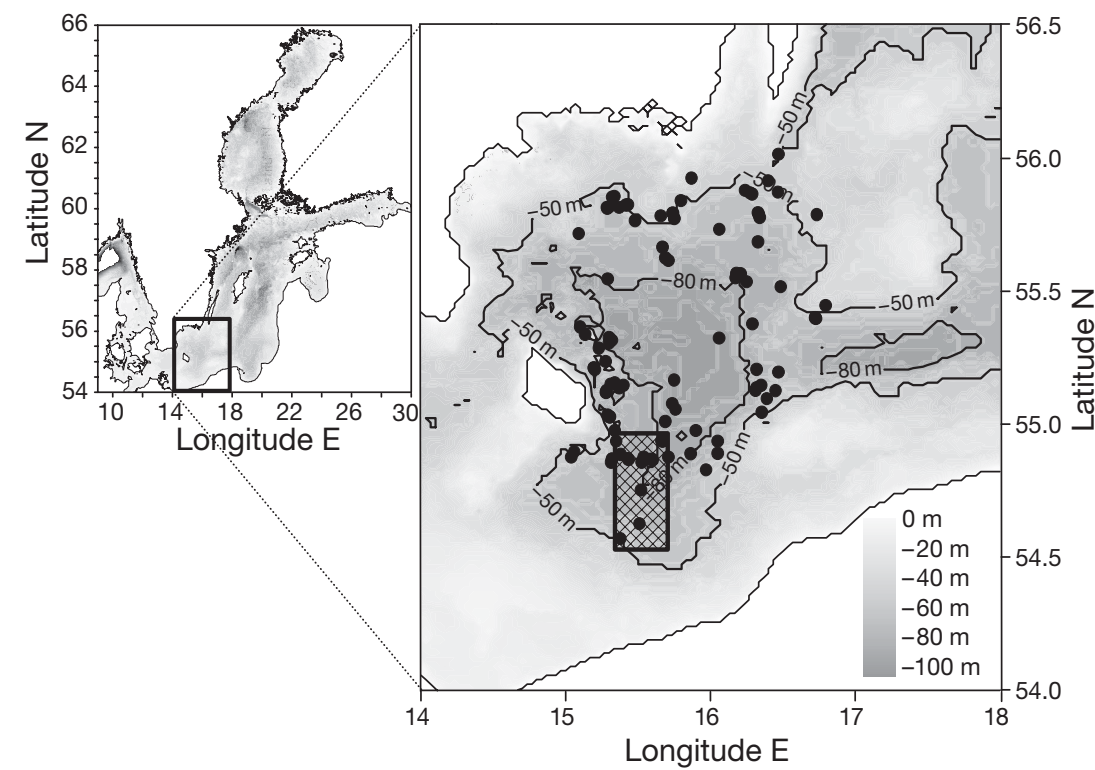

Fig. 1. Sampling area and trawl stations in the Bornholm basin of the central Baltic Sea. Cross-hatched rectangle: area sampled in December 1998

easterly winds followed by several weeks of strong westerly winds over the North Atlantic and Europe (Schinke \& Matthäus 1998). Such inflows are especially important for replenishment with oxygen-rich deep water, and a prolonged period of stagnation leads to the spread of hypoxic areas in the deep basins. During the past 3 decades, the frequency of these inflows has decreased drastically. Since 1976 major inflows have only occurred in 1993 and 2003 (ICES 2004).

The reduced frequency of inflows was accompanied by a change in the diet composition of adult cod Gadus morhua. The mass ratio of herring Clupea harengus L. to sprat Sprattus sprattus L. in the stomachs of adult cod in the central Baltic Sea was halved from ca. 1 in 1970 to 1975 to ca. 0.5 in 1986 to 1990 (Uzars 1994). However, this decrease was considerably less than the decrease in the sea, where the herring to sprat ratio decreased at least 3-fold (Parmanne et al. 1994, Köster et al. 2001). Thus, the observed changes in the cod diet are not simply a function of changes in the relative prey biomasses, and higher order mechanisms in the predator-prey relationship may be responsible. One mechanism that could explain this conservatism or stability of the cod diet composition is a change observed in the spatial distributions of the predator and prey species. The habitats of cod and its prey herring Clupea harengus overlap only partly in the Bornholm basin (Neuenfeldt 2002).

We developed conceptual models in which the aggregate diet composition of a predator population depends on habitat overlaps with 2 prey populations. These models were used to test the hypothesis that environmentally driven habitat overlaps regulate the ratio of herring to sprat in the aggregate diet of cod. Using the models, we demonstrated how the stability of the cod diet composition at increasing sprat abundance can result from incomplete cod-herring overlap.

\section{MATERIALS AND METHODS}

First we address the development of the conceptual models for the effect of habitat overlaps on the per capita population functional response (Chesson 1984), which we refer to as the aggregate functional response of the predator population. To understand the population consequences of changing overlaps, we also modelled how the prey abundances in the sea affect the aggregate diet in different situations of habitat overlaps. Second we address the empirical analyses conducted in order to estimate habitat overlaps and to test the model predictions using stomach content data.

Conceptual development. The term habitat volume $H$ describes the volume of a fish habitat, and is analogous to 'habitat quantity' (Gibson 1994). In accordance with Fretwell \& Lucas (1970), we defined habitat as any volume that is inhabitable by a fish species. The entire volume within each habitat is considered homogeneous regarding the physical features that are relevant for the survival of the species. $H$ is not related to the habitat of a single fish, but to the habitat of the whole population, in our case on a meso-scale contained by the ca. $100 \mathrm{~km}$ wide and max. $100 \mathrm{~m}$ deep Bornholm basin. We maintained the traditional assumption that predator and prey populations are considered homogeneously distributed within their habitats. The average density $\rho_{i}$ of prey species $i$ is determined by habitat volume $H_{i}$ and abundance $N_{i}$ :

$$
\rho_{i}=\frac{N_{i}}{H_{i}}
$$

We hypothesised that in the situation of 1 predator population and 2 prey populations (Fig. 2), the predator habitat $H_{\text {pred }}$ contains 3 strata: Stratum 0, where neither Prey 1 nor Prey 2 occur; Stratum 1, where only Prey 1 occurs; and Stratum 2, where both Prey 1 and Prey 2 occur. The functional responses in the different strata of the predator habitat are considered to depend on the stratum-specific prey densities.

We considered the individual functional responses identical for all individuals within a predator habitat stratum. The aggregate functional response $f_{i}^{*}$ with 


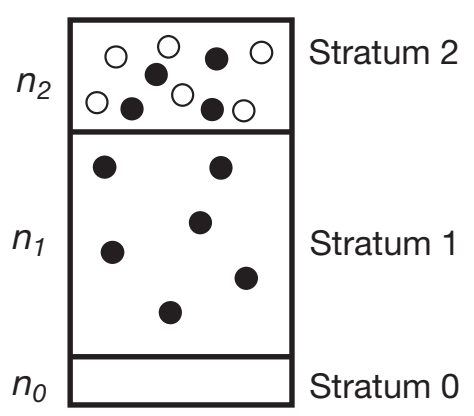

Fig. 2. Schematic representation of the predator habitat. -: Prey 1 ; O: Prey 2. Stratum $j$ contains $n_{j}$ predator individuals. In the Baltic case, strata correspond to vertical zones, with sprat as Prey 1 and herring as Prey 2

respect to prey species $i(i=1,2)$ is calculated as the weighted mean of the individual functional responses $f_{i}$ in the different strata of the predator habitat with the relative predator abundances $n_{j} / n$ in the strata as weighting factors:

$$
f_{i}^{*}=\sum_{j=0}^{2} \frac{n_{j}}{n} f_{i}\left(\rho_{1, j}, \rho_{2, j}\right) ; \text { with } n=\sum_{j=0}^{2} n_{j}
$$

where $\rho_{i, j}$ is the stratum-specific prey densities, $n$ is the total predator abundance and $n_{j}$ is the predator abundance in stratum $j$.

$n_{j} / n$ in each stratum can be represented by habitat overlaps. With the term $\mathrm{PEV}_{i}$ (potential encounter volume, i.e. the water volume in which prey $i$ and the predator co-occur; Neuenfeldt 2002), there are 2 ways to formulate habitat overlap, either from the predator or from the prey perspective:

$$
O_{i}=\frac{\mathrm{PEV}_{i}}{H_{\text {pred }}} ; \quad Q_{i}=\frac{\mathrm{PEV}_{i}}{H_{i}}
$$

The predator-prey overlap $O_{i}$ defines the fraction of the predator habitat, in which prey $i$ occurs, whereas the prey-predator overlap $Q_{i}$ (henceforth termed occupation) defines the fraction of the prey habitat in which prey individuals run the risk of encountering a predator. Due to the homogeneity assumption, the fraction that a given stratum has of the total predator habitat equals the fraction of the predator population in that particular stratum. The fraction of the predator population in each stratum is thus represented by predator-prey overlaps as follows:

$$
\frac{n_{j}}{n}=\left\{\begin{array}{c}
1-O_{1} ; j=0 \\
O_{1}-O_{2} ; j=1 \\
O_{2} ; j=2
\end{array}\right.
$$

The aggregate functional response ratio $f_{2}{ }^{*} / f_{1}{ }^{*}$ is a convenient starting point for analysing the population consequences of overlap dynamics. Using the habitat overlaps as weighting factors in Eq. (2) with the corresponding prey densities in the different strata, we obtained:

$$
\frac{f_{2}{ }^{*}}{f_{1}{ }^{*}}=\frac{O_{2} f_{2}\left(\rho_{1}, \rho_{2}\right)}{\left(O_{1}-O_{2}\right) f_{1}\left(\rho_{1}, 0\right)+O_{2} f_{1}\left(\rho_{1}, \rho_{2}\right)}
$$

$f_{2}{ }^{*} / f_{1}^{*}$ gives the average consumption rate of Prey 2 relative to the average consumption rate of Prey 1 by the predator, which can be related to stomach data. The right side of Eq. (5) is a function of functional response and overlap ratios. (Note: the impact of other food cancels out when the analysis is based on the ratio of aggregate functional responses.) Considering the overlap ratio $\mathrm{O}_{2} / \mathrm{O}_{1}$ as an independent environmental variable, Eq. (5) takes the form:

$$
\frac{f_{2}{ }^{*}}{f_{1}{ }^{*}}=\frac{a \frac{O_{2}}{O_{1}}}{1-b \frac{O_{2}}{O_{1}}}
$$

The coefficient a equals $f_{2}\left(\rho_{1}, \rho_{2}\right) / f_{1}\left(\rho_{1}, 0\right)$, i.e. the consumption rate of Prey 2 in Stratum 2 relative to the consumption rate of Prey 1 in Stratum 1. The aggregate functional response ratio increases linearly with increasing $O_{2} / O_{1}$, if $b$ is 0 . The coefficient $b$, representing $1-f_{1}\left(\rho_{1}, \rho_{2}\right) / f_{1}\left(\rho_{1}, 0\right)$, becomes 0 when $f_{1}\left(\rho_{1}, \rho_{2}\right)$ equals $f_{1}\left(\rho_{1}, 0\right)$. This is only the case if the consumption rate of Prey 1 is independent of the density of Prey 2. If the consumption rate of Prey 1 depends on the densities of both Prey 1 and Prey 2, then the aggregate functional response ratio continues to increase with increasing $O_{2} / O_{1}$ at a rate that accelerates from a minimum of $a$ for $O_{2} / O_{1}=0$ to a maximum of $a(1-b)^{-2}$ for $O_{2} / O_{1}=1$. Thus, as the overlap ratio increases, the aggregate functional response ratio increases at a rate that is a factor of $\left[f_{1}\left(\rho_{1}, 0\right) / f_{1}\left(\rho_{1}, \rho_{2}\right)\right]^{2}$ higher for a situation near common overlap $\left(\mathrm{O}_{2} / \mathrm{O}_{1}=1\right)$ than for a situation near 0 overlap for Prey $2\left(O_{2} / O_{1}=0\right)$.

The coefficients $a$ and $b$ are not constant in time. They will change with changing prey abundance ratios and habitat ratios according to how the functional response of the predator actually depends on prey densities. Furthermore, $a$ and $b$ in Eq. (6) cannot be considered independent of $O_{2} / O_{1}$ if the habitat ratio varies with the overlap ratio, because in this case the prey densities will not be independent of the overlaps. It becomes natural to consider $O_{2} / O_{1}$ divided by the habitat ratio $H_{2} / H_{1}$, which results in the occupation ratio $Q_{2} / Q_{1}$ based on Eq. (3), as the relevant environmental index:

$$
\frac{f_{2}{ }^{*}}{f_{1}{ }^{*}}=\frac{a_{H} \frac{Q_{2}}{Q_{1}}}{1-b_{H} \frac{Q_{2}}{Q_{1}}}
$$

The relationships to the coefficients in Eq. (6) become $a_{H}=a H_{2} / H_{1}$ and $b_{H}=b H_{2} / H_{1}$. 
Functional response: We considered 2 well-known and generic functional response models, both representing the simplest possible extensions from the linear (or Type 1) response (Holling 1959). Our first model, the Holling Type 2 functional response, expanded to 2 species (Murdoch 1973), accounts for prey-specific handling times $h_{i}$, i.e. using the generalised Holling's disk equation:

$$
f_{i}\left(\rho_{1}, \rho_{2}\right)=\frac{\delta \alpha_{i} \rho_{i}}{1+\delta\left(\alpha_{1} h_{1} \rho_{1}+\alpha_{2} h_{2} \rho_{2}\right)}
$$

The parameter $\delta$ is an overall searching rate, and $\alpha_{i}$ is a preference measure (Chesson 1978). Alternatively, we can express this and, in general, any form of functional response as the total prey consumption $f_{T}=f_{1}+f_{2}$ multiplied by the proportion of the diet made up by species $i$. Since this diet proportion is defined by the preferences $\alpha_{1}$ and $\alpha_{2}\left(=1-\alpha_{1}\right)$ we obtained:

$$
f_{i}\left(\rho_{1}, \rho_{2}\right)=f_{T} \frac{\alpha_{i} \rho_{i}}{\alpha_{1} \rho_{1}+\alpha_{2} \rho_{2}}
$$

where $f_{T}$ in general will depend on $\alpha_{1}$ and $\alpha_{2}$ (Chesson 1984). The second functional response model is simply specified by considering $f_{T}$ constant. This is an active response model, because the predator keeps the rate of food consumption constant by actively modifying the searching rate $\delta$, so search rate becomes a function of prey densities (Chesson 1984). In a case with considerable difference in average prey mass $\left(w_{2}>w_{1}\right), f_{i}$ is replaced by $f_{i} W_{\mathrm{i}}$ in Eq. (9) to model a constant rate of average food consumption $f_{T}=\Sigma f_{i} W_{\mathrm{i}}$ by mass rather than numbers. The aggregate functional response ratio is then quantified directly as the prey-specific mass ratio of stomach content.

Population consequences: Focusing on the effect of changes in the prey abundance ratio $N_{2} / N_{1}$, Eq. (5) can be written as:

$$
\frac{f_{2}{ }^{*}}{f_{1}{ }^{*}}=\frac{\frac{O_{2}}{O_{1}} \frac{f_{2}\left(\rho_{1}, \rho_{2}\right)}{f_{1}\left(\rho_{1}, \rho_{2}\right)}}{\frac{O_{2}}{O_{1}}+\left(1-\frac{O_{2}}{O_{1}}\right) \frac{f_{1}\left(\rho_{1}, 0\right)}{f_{1}\left(\rho_{1}, \rho_{2}\right)}}
$$

In the numerator, the consumption rate of Prey 2 as compared to Prey 1 (in Stratum 2) can be expressed by:

$$
\frac{f_{2}\left(\rho_{1}, \rho_{2}\right)}{f_{1}\left(\rho_{1}, \rho_{2}\right)}=A \frac{H_{1}}{H_{2}} \frac{N_{2}}{N_{1}}
$$

Similarly, $f_{1}\left(\rho_{1}, 0\right) / f_{1}\left(\rho_{1}, \rho_{2}\right)$ in Eq. (10), the consumption rate of Prey 1 (in Stratum 1) compared to the consumption rate of Prey 1 (in Stratum 2) is expressed by:

$$
\frac{f_{1}\left(\rho_{1}, 0\right)}{f_{1}\left(\rho_{1}, \rho_{2}\right)}=1+B \frac{H_{1}}{H_{2}} \frac{N_{2}}{N_{1}}
$$

Eq. (10) can be re-written as:

$$
\frac{f_{2}{ }^{*}}{f_{1}{ }^{*}}=\frac{A \frac{H_{1}}{H_{2}} \frac{O_{2}}{O_{1}} \frac{N_{2}}{N_{1}}}{1+B \frac{H_{1}}{H_{2}}\left(1-\frac{O_{2}}{O_{1}}\right) \frac{N_{2}}{N_{1}}}
$$

This alternative formulation to Eq. (6) is with equal coefficient ratios $\left(A / B=a / b=a_{H} / b_{H}\right)$. In the Type 2 functional response model, $A$ becomes prey density independent $\left(A=\alpha_{2} / \alpha_{1}\right)$, whereas $B=\delta h_{2} \alpha_{2} \rho_{1} /(1+$ $\left.\delta h_{1} \alpha_{1} \rho_{1}\right)$ depends on the density of Prey $1\left(\rho_{1}=N_{1} / H_{1}\right)$. In the active response model, both coefficients are density independent $\left(A=B=\alpha_{2} / \alpha_{1}\right)$. (Note: $A$ is a factor of $W_{1} / w_{2}$ smaller than $B$ in the case of the active response model with constant mass rate of food consumption (cf. $a$ and b, Eq. 6 and see Table 3).

Empirical analyses. Analyses were conducted in 4 steps. (1) For each species we determined vertical thresholds of salinity and oxygen saturation within which the species occurred by: (a) investigating whether the permanent halocline is the upper depth limit during daytime and (b) relating survey-based catch rates to oxygen saturation below the halocline. (2) We calculated habitat volumes and the resulting habitat overlaps and occupations between the cod Gadus morhua and the 2 prey species (herring Clupea harengus and sprat Sprattus sprattus). (3) We tested for the predicted effect of habitat overlap ratio on cod consumption of herring relative to sprat using habitat occupations and cod stomach contents, and identified the more probable of the 2 functional response models. (4) We considered the population consequences using the more probable functional response model.

We used 6 different datasets. (1) Catch data from combined demersal and pelagic trawl hauls with RV 'Dana' in December 1998 in the Bornholm basin; (2) trawl hauls with RV 'Dana' in February/March 1998 to 2001 with concomitant oxygen data; (3) oxygen profiles for 1958 to 2004 ; (4) high-resolution spherical grid topography of the Bornholm basin; (5) individual stomach contents of cod from the Bornholm basin collected in March 1984 and 1993; (6) pooled stomach contents of cod collected in February/March 1977 to 1993.

Habitat thresholds: We determined thresholds of the habitats of cod, herring and sprat for the daytime only, because herring and sprat tend to perform diel vertical migrations, residing during night in the surface water out of contact with cod and only during daytime are they in the waters below the surface layer (Nilsson et al. 2002). Whether the apparent absence of all 3 species from the surface water is associated with the low temperatures $\left(<4^{\circ} \mathrm{C}\right.$ in March in the surface water compared to 6 to $9^{\circ} \mathrm{C}$ in the intermediate and bottom layers) or low salinity cannot be tested statistically on the present data, because temperature and salinity values are strongly correlated. We used catch data 
from combined demersal and pelagic trawl hauls with RV 'Dana' in December 1998 in the Bornholm basin (Fig. 1) to test for the presence of cod, herring and sprat in the surface and intermediate waters. Daytime EXPO trawl hauls for $0.5 \mathrm{~h}$ at approximately 3.5 knots were performed through the bottom layer below $60 \mathrm{~m}$ depth ( $\mathrm{n}=9$, average vertical opening $=6.5 \mathrm{~m}$ ), and pelagically in the intermediate water between 40 and $60 \mathrm{~m}$ depth ( $\mathrm{n}=5$, average vertical opening $=13.5 \mathrm{~m}$ ), as well as in the surface layer above $40 \mathrm{~m}$ depth $(\mathrm{n}=3$, average vertical opening $=17.5 \mathrm{~m}$ ).

To estimate the lower boundaries of the vertical distributions of the 3 species, data from the trawl hauls with RV 'Dana' in February/March 1998 to 2001 were used (Fig. 1). Daytime hauls of $1 \mathrm{~h}$ were carried out in 1998 and 1999 between 45 and 95 m depth, using a Granton bottom trawl with a vertical opening of approximately $4 \mathrm{~m}$, towed at 3.5 knots. Additionally, in 2000 and 2001 a TV3 trawl with a vertical opening of approximately $10 \mathrm{~m}$ was used to make $0.5 \mathrm{~h}$ hauls. The corresponding TV3 trawl catches in numbers were multiplied by 2 to raise the catches to a tow duration of $1 \mathrm{~h}$ in order to maintain comparability with the Granton data. Distribution boundaries were estimated by trawl type and also combined for both types to investigate whether Granton and TV3 data could be combined for the purpose of this study despite the greater opening of the TV3. Vertical profiles of oxygen saturation, salinity and temperature were obtained at each trawl station using a SeaBird CTD system. Bottle samples were taken for calibrating the oxygen saturation using Winkler titrations and for conductivity using an AutoSal Guildline Model 8400B salinometer.

We formulated a statistical model for daytime catch rates below the halocline to estimate oxygen saturation thresholds for predator and prey. For catch rates $>0\left(\mathrm{n} \mathrm{h}^{-1}\right)$, a log-normal distribution was assumed, with $\ln (\mu)$ as the mean of the log-transformed catch rates and $\sigma^{2}$ as the variance of the log-transformed catch rates. The expected value for the non-empty catches is $\mu \exp \left(\sigma^{2} / 2\right)$, where $\mu$ depends on oxygen saturation, while $\sigma^{2}$ is assumed independent. Assignment of $\mu$ to a given oxygen saturation $p$ was modelled as a standard sigmoid:

$$
\mu(p)=\frac{C}{1+\exp \left[-\beta\left(p-p_{0.5}\right)\right]}
$$

At oxygen saturations close to a lethal limit, $\mu$ is close to 0 , while around $p=p_{0.5}, \mu$ is ca. $0.5 C$. $C$ is the saturation level of the sigmoid. When oxygen is abundant $\mu$ is independent of $p$ and equals $C$. The coefficient $\beta$ expresses the specific rate at which $\mu$ increases around $p=p_{0.5}$.

We modelled the probability of empty hauls as: $P($ CPUE $=0 \mid p)=\exp [-\gamma \mu(p)]$. The constant $\gamma$ was introduced to account for each species' different propensity to aggregate. Aggregation or schooling leads to an increased probability of empty hauls, because mean distance to the nearest fish (in a school) from the centre line of the trawl path is greater than compared to non-schooling fish. The expected catch per unit of effort (CPUE) including empty hauls was consequently:

$$
E(\mathrm{CPUE} \mid p)=\mu(p) \exp \left(\frac{\sigma^{2}}{2}\right)\{1-\exp [-\gamma \mu(p)]\}
$$

Maximum-likelihood-based estimates of the parameters and their standard errors were derived using the R programming language (www.r-project.org).

We set the critical oxygen threshold $p_{\mathrm{c}}$ to the oxygen saturation at which the increase in slope of the oxygen sigmoid function was maximal. Thus, $p_{\mathrm{c}}$ is mathematically defined as the oxygen saturation at which the third derivative of $E(\mathrm{CPUE} \mid p$ ) with respect to $p$ is 0 and the second derivative is positive. Considering $p_{\mathrm{c}}$ as a function of the unknown true model parameters, a consistent estimate of the standard error of the estimated $p_{\mathrm{c}}$ was derived by Taylor expansion of the thresholds around the 'true' parameters.

Habitat volumes and PEV: For the period from 1958 to 2004, oxygen profiles from March are available (MacKenzie et al. 2000, Hinrichsen pers. comm., Leibniz Insititute of Marine Sciences, Kiel, Germany), but without concomitant catch data. Therefore, we assumed $p_{\mathrm{c}}$ to be constant for each species in this period. The depth $d_{\mathrm{c}}$ at which oxygen saturation equalled $p_{\mathrm{c}}$ was calculated by linear interpolation for each year. The habitat volumes $H_{\text {cod }}$ (for cod), $H_{\text {her }}$ (for herring) and $H_{\text {spr }}$ (for sprat) were obtained by integrating the volumes between the upper and lower depth boundaries, using high-resolution spherical grid topography (Seifert \& Kayser 1995). As a further restriction on $H_{\text {cod, }}$ the depth at which pressure was $75 \%$ of the pressure at the bottom was used as the upper boundary of the free vertical range. Cod that are neutrally buoyant at bottom depth would have to use energy to maintain depth outside this free vertical range (Harden-Jones \& Scholes 1985). Potential encounter volumes were obtained using the same integration method as that for $H_{\text {cod, }}$, but using the threshold values for herring and sprat.

Concomitant data on cod stomach contents were unavailable for most cases, so we calculated the average habitat volumes for February/March in order to relate these to the average February/March cod consumptions of herring and sprat from the stomach database. For years in which CTD data from February or March were unavailable, we substituted data from late January or early April.

Cod diet: Data on individual cod stomach contents from the Bornholm basin with concomitant hydro- 


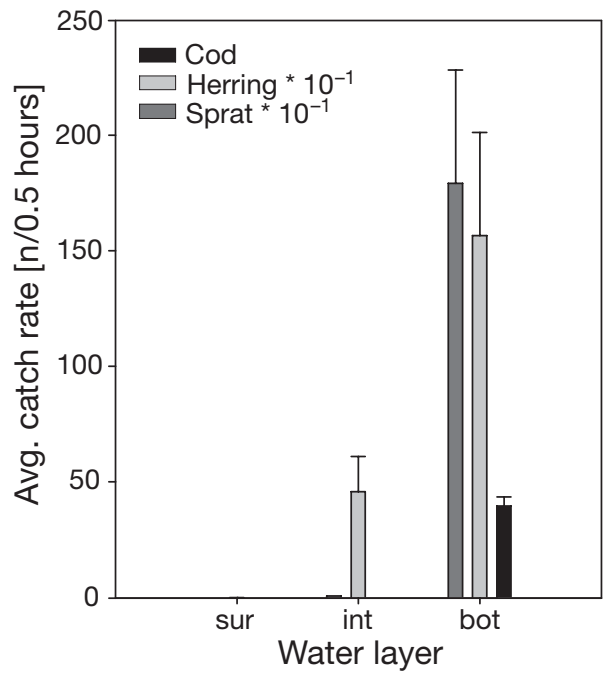

Fig. 3. Daytime catch rates in the 3 different water layers during daytime in December 1998. sur: surface; int: intermediate; bot: bottom. Error bars $=+1 \mathrm{SE}$

graphic information exist for March 1984 and 1993, and were extracted from the ICES database on cod stomach contents for the Baltic Sea (ICES 1999). The data included observed mass of stomach content by cod age and prey item, including 2 digestion stages for each herring and sprat (Stage 1: fresh, total length still measurable; Stage 2: further digested). Digestion Stage 1 lasts about $12 \mathrm{~h}$ at a temperature of about $4^{\circ} \mathrm{C}$ (Johansen et al. 2004).

The average of the square root of the total stomach content, $\overline{\sqrt{S}}\left[g^{0.5}\right]$, was chosen as the best measure for the average ration, because the mean stomach evacuation of cod is adequately described by a square root model (Andersen 2001). The $95 \%$ confidence limits of $\overline{\sqrt{S}}$ were estimated using a bootstrap method (Efron 1993), with 1000 replicates. The number of empty stomachs per $10 \mathrm{~cm}$ length group was considered to be binomially distributed. The $95 \%$ confidence limits of the estimated fraction of empty stomachs, $P(S=0)$, were estimated accordingly.

Stomach data are usually submitted as pooled values by ICES subdivisions to the ICES. The Bornholm basin belongs to ICES Subdivision 25. We did not have access to most of the individual stomach data, except for 1984 and 1993, or more accurate sampling positions. Therefore, the time series used to approximate the relative aggregate functional response ratio were based on pooled cod stomach contents collected in February/March from ICES Subdivision 25 between 1977 and 1993 (ICES 1999). In the stomachs of 4 to 6 yr old cod, the average number ratio of herring to sprat, $\overline{r_{\text {her }}} / \overline{r_{\text {spr }}}$, was estimated as the total mass of herring divided by the total mass of sprat times the body mass ratio of sprat to herring $w_{\text {her }} / w_{\text {spr }}$. Body masses were calculated as the weighted means of weight-at-age (ICES 1999), weighted by the abundance of prey in Age Groups 1 to 7 (ICES 1999).

We consider the observed ratio of herring to sprat in the stomach to be the best possible approximation for the relative aggregate functional response ratio:

$$
\frac{f_{\mathrm{her}^{*}}{ }^{*}}{{f_{\mathrm{spr}}}^{*}} \cong \frac{\overline{r_{\mathrm{her}}}}{\overline{r_{\mathrm{spr}}}}
$$

Note that $\overline{r_{\text {her }}}$ and $\overline{r_{\text {spr }}}$ refer to the average amount of prey consumed during some average stomach evacuation time. Given that this time window spans a period of a few days, we consider the observed diet representative of those regions in which the cod were caught.

\section{RESULTS}

\section{Habitat thresholds}

None of the species were observed in the surface layer during daytime in December 1998 (Fig. 3). Cod Gadus morhua were only caught in the bottom layer at salinities $\geq 9 \mathrm{psu}$, which we used as the salinity threshold to determine the dynamic upper vertical habitat limit. Herring Clupea harengus and sprat Sprattus sprattus occurred additionally in the intermediate layer. Assuming that salinity increases at a rate of $0.2 \mathrm{psu} \mathrm{m}^{-1}$ below the surface layer, we subtracted $10 \mathrm{~m}$ from the $9 \mathrm{psu}$ depth to determine the upper vertical habitat limit for herring and sprat, allowing for movement up into the intermediate layer but not beyond into the surface water, which has a salinity around 7 psu.

The lower boundaries of the vertical distributions of each species were related to low oxygen saturation. The empirically derived critical oxygen limit $p_{\mathrm{c}}$ based on Eq. (15) was $50.6 \pm 6.4 \%$ (SE) saturation for herring, $16.9 \pm 2.4 \%$ saturation for sprat and $10.5 \pm 3.2 \%$ (SE) saturation for cod. For all species it could not be rejected that the logarithmic model (Table 1) residuals were normally distributed (Kolmogorov-Smirnov test,

Table 1. Estimated parameters $( \pm \mathrm{SE})$ for the model that relates the expected catch per unit effort, including 0 hauls, to oxygen saturation (see 'Materials and methods' for parameter explanation)

\begin{tabular}{|c|c|c|c|}
\hline Parameter & Cod & Herring & Sprat \\
\hline$C$ & $63 \pm 12$ & $786 \pm 273$ & $3409 \pm 595$ \\
\hline$\beta$ & $0.1154 \pm 0.0349$ & $0.0811 \pm 0.0119$ & $0.1776 \pm 0.0533$ \\
\hline$p_{0.5}$ & $25.6 \pm 5.7$ & $66.7 \pm 8.3$ & $24.0 \pm 3.3$ \\
\hline$\sigma$ & $1.3959 \pm 0.1007$ & $1.6305 \pm 0.1227$ & $1.9143 \pm 0.1471$ \\
\hline$\gamma$ & $0.1602 \pm 0.0675$ & $0.0685 \pm 0.0224$ & $0.0013 \pm 0.0001$ \\
\hline
\end{tabular}


$\mathrm{p}<0.05)$. Catch rates of all 3 species from March 1998 to 2002 were very low for both trawl types, when the oxygen saturation was below these threshold values, and were highly variable above the thresholds (Fig. 4). For cod and sprat the predicted CPUEs at $p_{\mathrm{c}}$ were not significantly different from 0 (cod: $19 \pm 10$ [SE], sprat $2935 \pm 1847$ ), but for herring the CPUE at $p_{\mathrm{c}}, 633 \pm 183$, was significantly greater than 0 . We also estimated $p_{\mathrm{c}}$ for cod and herring separately for each gear type by running the model with either the GRANTON or the TV3 data. The $p_{\text {c }}$ for sprat could not be estimated
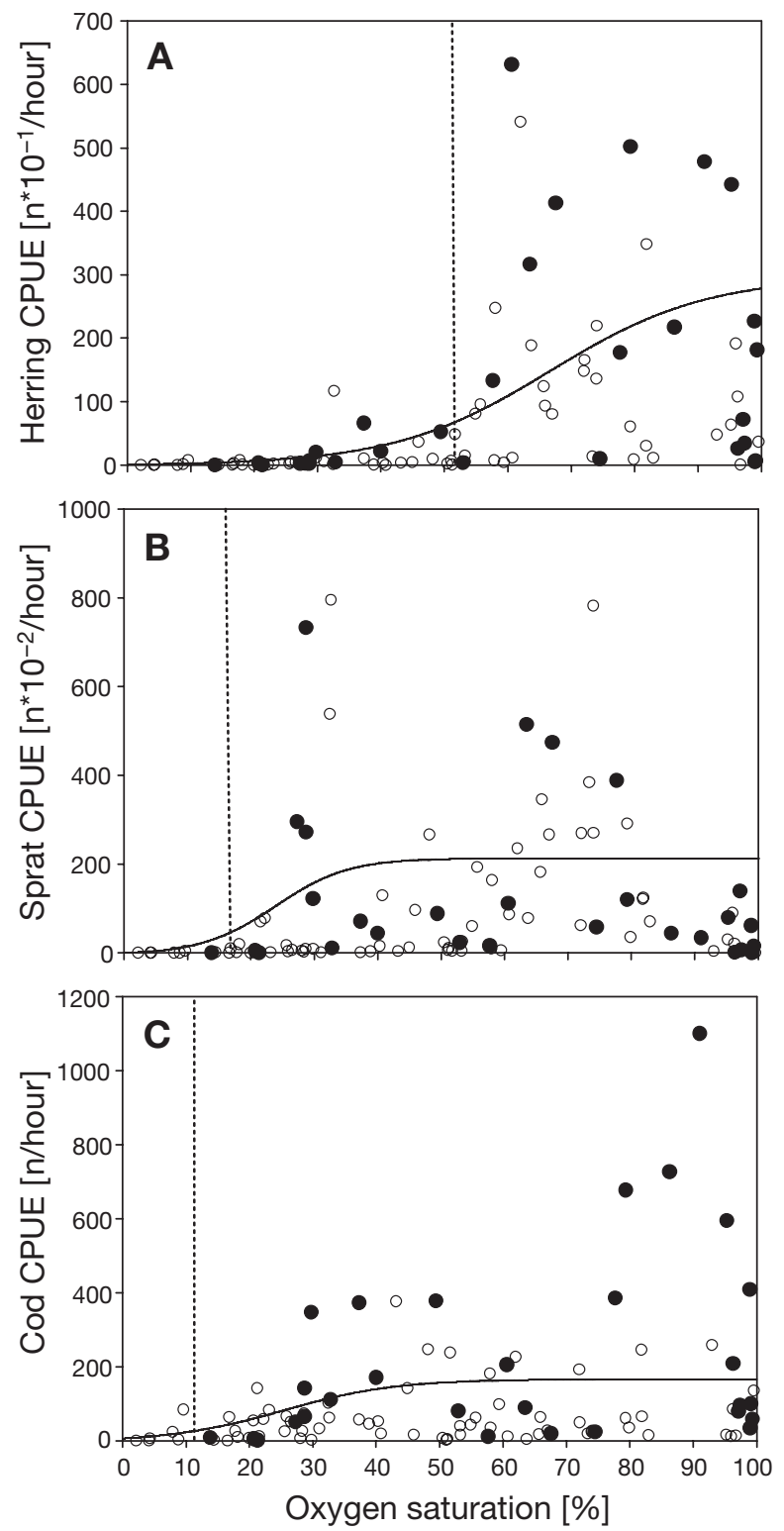

Fig. 4. Catch rates of (A) herring, (B) sprat and (C) cod relative to oxygen saturation. - GRANTON trawl; O: TV3 trawl. Solid lines: model estimates of mean catch rates; vertical dashed lines: threshold saturation $\left(p_{\mathrm{c}}\right)$. CPUE: catch per unit effort exclusively from the TV3 data. For cod and herring, the $p_{\mathrm{c}}$ estimates did not differ significantly by gear type ( $t$-test, $\mathrm{p}>0.1$ ).

\section{Habitat volumes and PEV}

The depth at which oxygen saturation is $50.6 \%$, in the following denoted as $d_{50}$, separates cod with the potential to encounter both herring and sprat from cod which cannot encounter herring. Based on the estimated oxygen thresholds, we divided the cod habitat into 3 different strata. At the bottom, in Stratum 0 with oxygen saturation $<16.9 \%$, herring and sprat do not co-occur with cod. In Stratum 1 with oxygen saturation $<50.6$ and $>16.9 \%$, cod co-occur only with sprat. In Stratum 2 with oxygen saturation $>50.6 \%$, cod co-occur with sprat and herring.

Applying the time series of CTD casts from the centre of the basin, we classified the vertical profiles of oxygen saturation in the Bornholm basin into 4 different types (Fig. 5): (1) 'Stagnation' (Fig. 5A): characterised by a linear decrease of oxygen saturation in the vicinity of $d_{50}$. The profiles for the basin from 1994 to 2001 belonged to this type (Fig. 6). (2) 'Inflow' (Fig. 5B): oxygen saturation also decreases with in-
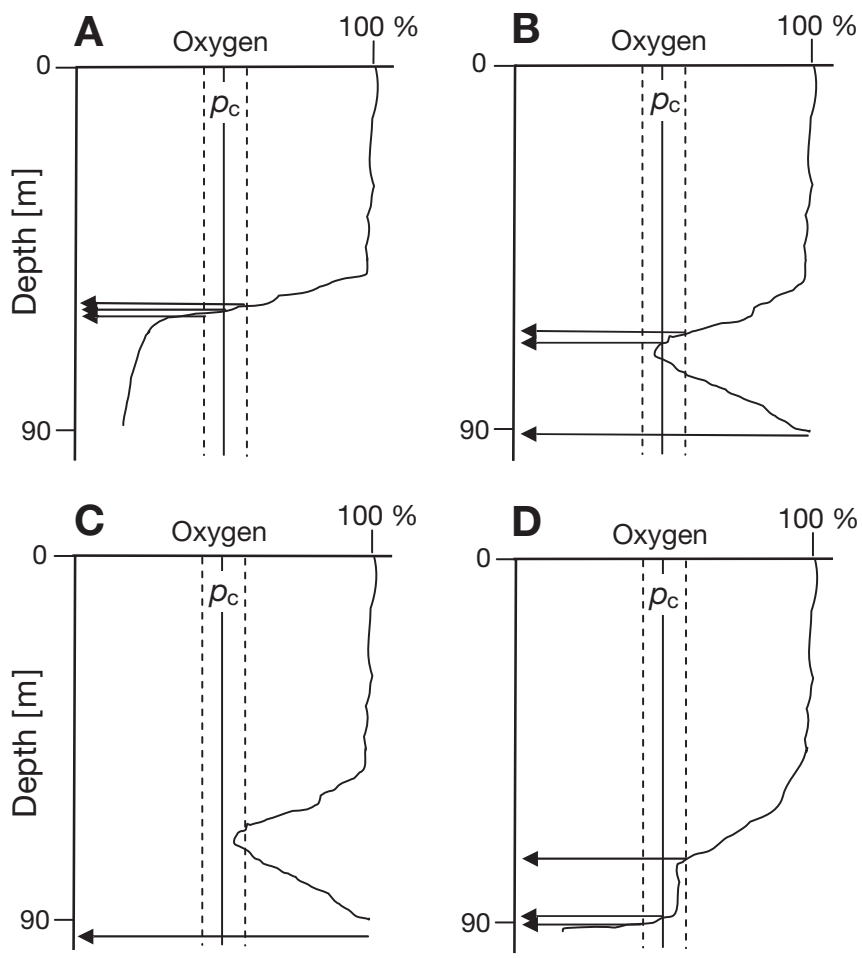

Fig. 5. Different types of vertical oxygen saturation profiles: (A) stagnation, (B) inflow, (C) major inflow and (D) intrusion. Arrows: herring oxygen threshold depth $\left(d_{50}\right)$ and its confidence limits, resulting from the confidence limits of threshold saturation $\left(p_{\mathrm{c}}\right)$ for herring 


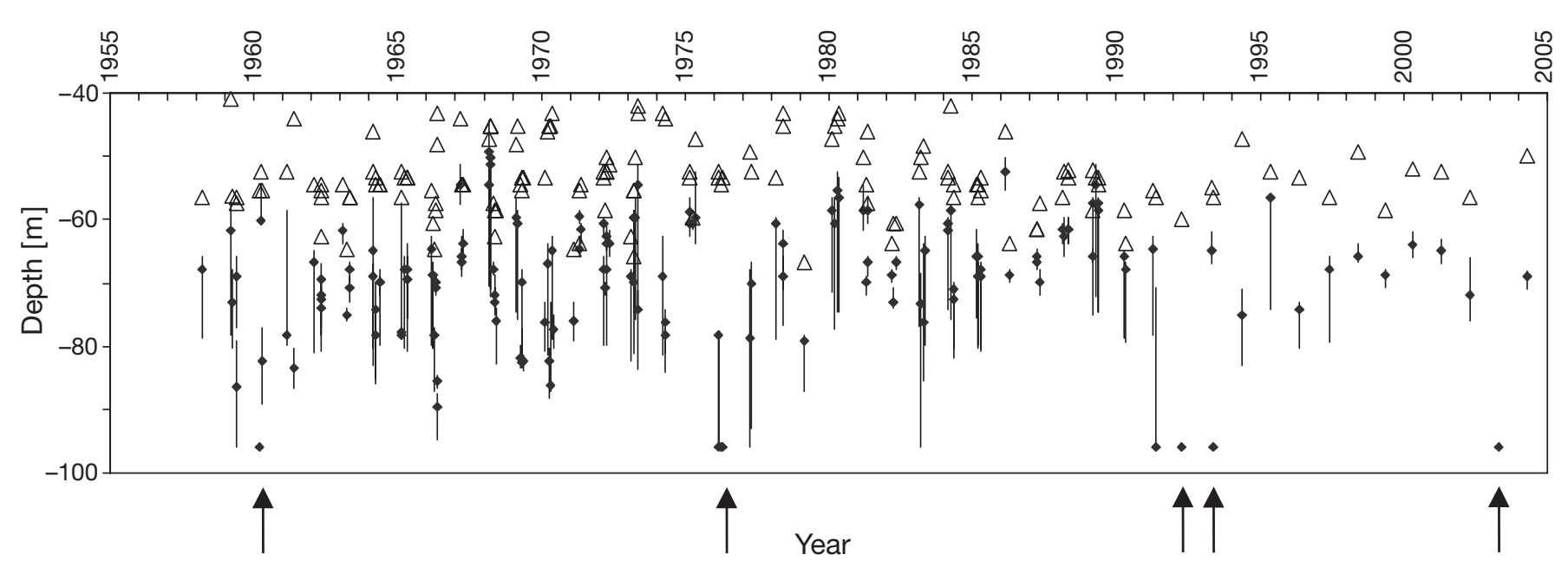

Fig. 6. Time series of the depths at which salinity was 9 psu $(\Delta)$ and of the herring oxygen threshold depth $\left(d_{50}\right)(\bullet$, with confidence limits). Arrows: major inflows into the Bornholm basin

creasing depth. However, in contrast to the stagnation profile, oxygen saturation increases again from some depth below $d_{50}$ due to the inflowing oxygenated water mass. (3) 'Major inflow' (Fig. 5C): oxygen saturation at all depths is above $p_{\mathrm{c}}$, which means that $d_{50}$ practically does not occur. This profile type is the only one that corresponds to a full overlap of $H_{\text {cod }}$ and $H_{\text {her }}$. (4) 'Intrusion' (Fig. 5D): characterised by an interruption in the decrease of the oxygen saturation at depth due to water from the Gdansk basin, intruding between the halocline and the bottom layer. This intruding water cannot increase the oxygen saturation at the bottom, because it is not dense enough due to its relatively low salinity.

Depending on the profile type, the confidence limits of $p_{\mathrm{c}}$ for herring differ when transformed into the confidence limits of $d_{50}$. For the profile type Stagnation, the $d_{50}$ confidence limits are approximately symmetric and comparatively small when compared to the other profile types (Fig. 5A). For the profile type Inflow, the lower confidence limit of $p_{\mathrm{c}}$ may not occur, in which case the lower confidence limit of $d_{50}$ reaches down to the bottom (Fig. 5B). The confidence interval of $d_{50}$ that corresponds to the profile type Intrusion (Fig. 5D) is asymmetric and the lower error bar is considerably smaller than the upper error.

Inflows affect the depth of 9 psu salinity, the value of $d_{50}$ and also the reliability of $d_{50}$ as a measure for the $H_{\text {her }}$ and the cod-herring overlap. In the absence of new inflows, $d_{50}$ returns to its average level within the first year following major inflows. Since the major inflow in 1976, $d_{50}$ has largely been in the 60 to $70 \mathrm{~m}$ range (Fig. 6).

During the past $46 \mathrm{yr}$, the February/March habitat volumes of cod and its prey varied without any apparent overall trend (Fig. 7A). Major inflows (Fig. 6)
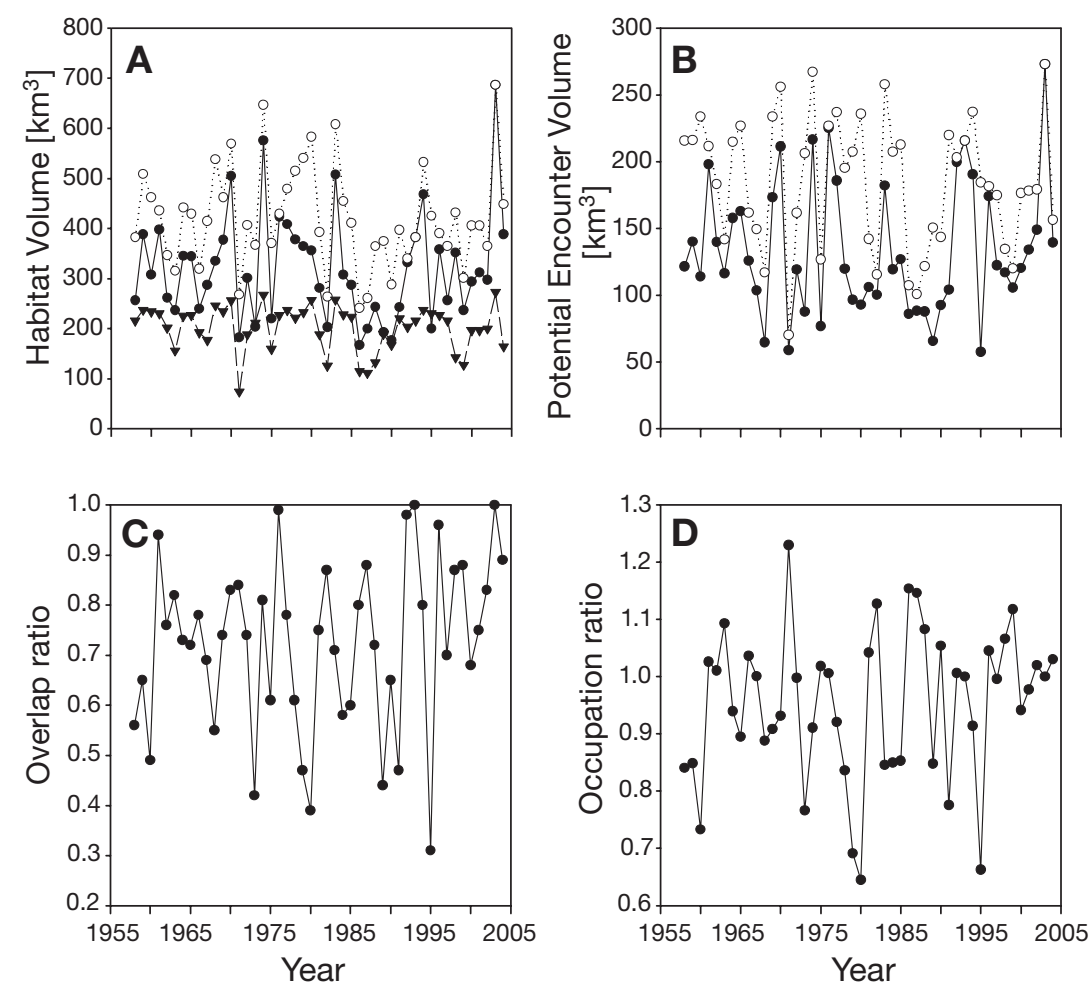

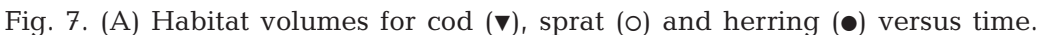
(B) Potential encounter volume for herring $(\bullet)$ and sprat $(\mathrm{O})$, and the resulting $(\mathrm{C})$ herring to sprat overlap ratio $O_{\text {her }} / O_{\text {spr }}$ and (D) occupation ratio $Q_{\text {her }} / Q_{\text {spr }}$ during the study period 
have led to maximal habitat volumes (with the exception of 1960 when no inflow into the basin was registered before early April). However, maximum habitat volumes were observed in 1974 to be caused by a relatively thin surface layer associated with a very shallow halocline. All species exhibited a decrease in habitat volumes during the absence of inflow events in the 1980s.

The PEV between cod and herring $\left(\mathrm{PEV}_{\mathrm{her}}\right)$ ranged between $57 \mathrm{~km}^{3}$ in 1995 and $225 \mathrm{~km}^{3}$ in 1976, with an average of $130 \mathrm{~km}^{3}$ (Fig. $7 \mathrm{~B}$ ). The PEV between cod and sprat always included $\mathrm{PEV}_{\text {her }}$ and ranged between $70 \mathrm{~km}^{3}$ in 1971 and $257 \mathrm{~km}^{3}$ in 1974, with an average of $180 \mathrm{~km}^{3}$ (Fig. 7B).

The resulting overlap ratio $O_{\text {her }} / O_{\text {spr }}$ ranged from 0.31 in 1995 to 1 in major inflow years. The average overlap ratio was 0.72 (Fig. $7 \mathrm{C}$ ). The prey density ratio is not independent of the overlap ratio, since the habitat ratio in our case decreased with the overlap ratio $\left[H_{\text {spr }} / H_{\text {her }}=1.29\left(1-O_{\text {her }} / O_{\text {spr }}\right)+1 ; \mathrm{n}=44 \mathrm{yr}, \mathrm{p}<0.0001\right.$, $\left.\mathrm{r}^{2}=0.75\right]$. Therefore, focus is rather placed on the occupation ratio $Q_{\mathrm{her}} / Q_{\mathrm{spr}}$, which varied between 0.64 in 1980 and 1.23 in 1971, with an average of 0.95 .

\section{Cod diet}

The individually sampled cod stomach content data reflect the predicted habitat thresholds. In March 1984, the oxygen profile was of the stagnation type, and $d_{50}$ lay at $73 \pm 2 \mathrm{~m}$ depth. All 209 individual cod stomachs from March 1984 were sampled from below $d_{50}$, and none contained herring. In March 1993, the oxygen profile was of the inflow type at the sites where cod stomachs were collected from below $d_{50}$, although the profile was already of the major inflow type at many other locations of the basin. The stomachs of cod caught above $d_{50}$ contained both fresh herring and fresh sprat, while stomachs sampled from below $d_{50}$ did not contain herring.

The individual stomach content data support the active response model, because they indicate a constant mass rate of food consumption. Apart from very large $\operatorname{cod}(>70 \mathrm{~cm})$, the fraction of empty stomachs and the average of the square-rooted stomach content in March 1993 did not differ significantly for cod caught above and below $d_{50}$ (Table 2 ).

Considering the pooled stomach content data from 1977 to 1993 (Fig. 8), the variability in the ratio of consumed herring to sprat can, to some extent, be explained by using the occupation ratio $Q_{\mathrm{her}} / Q_{\mathrm{spr}}$ as the key environmental variable and applying Eq. (7). The model relating number ratio of herring to sprat in cod stomachs to changes in the occupation ratio (Fig. 8A) was highly significant $\left(\mathrm{p}<0.0004, \mathrm{r}^{2}=0.35\right)$. The coefficient $a_{H}$ was estimated at $0.029 \pm 0.014( \pm \mathrm{SE})$, and $b_{H}$ at $0.78 \pm 0.06$. When the number ratio was replaced by the mass ratio of herring to sprat in cod stomachs (Fig. 8B), the model was also highly significant ( $\mathrm{p}<$ $\left.0.0005, r^{2}=0.37\right)$. In this case, $a_{H}$ was estimated at $0.15 \pm 0.08$, and $b_{H}$ was again estimated at $0.78 \pm 0.06$.

The coefficient ratio $b_{H} / a_{H}$ equals $\left[f_{1}\left(\rho_{1}, 0\right)-f_{1}\left(\rho_{1}\right.\right.$, $\left.\left.\rho_{2}\right)\right] / f_{2}\left(\rho_{1}, \rho_{2}\right)$, which is the additional number of sprat consumed in Stratum 1 in order to compensate for the lack of herring, relative to the number of herring consumed in Stratum 2. In the Type 2 functional response

Table 2. Estimated fraction of empty stomachs, $P(S=0)$ (with $95 \%$ confidence limits), and the average of the square roots of the stomach contents $\left(g^{0.5}\right.$, including both empty and non-empty stomachs) (with $95 \%$ confidence limits) for different cod length classes above and below the herring oxygen threshold in 1993. Weight percentages display fresh herring (HER1), fresh sprat (SPR1), further digested herring (HER2), further digested sprat (SPR2) and invertebrates (INVE), found in cod stomachs above and below the herring threshold in 1993. The diets may not always add up to $100 \%$, because the fraction of other fish is not listed

\begin{tabular}{|c|c|c|c|c|c|c|c|c|}
\hline Length $(\mathrm{cm})$ & $\mathrm{n}$ & $P(S=0)$ & $\overline{\sqrt{S}}$ & HER1 & SPR1 & HER2 & SPR2 & INVE \\
\hline \multicolumn{9}{|l|}{ Stratum 2} \\
\hline$\leq 30$ & 46 & $0.11(0.04,0.24)$ & $0.71(0.56,0.88)$ & 0 & 0 & 0 & 0 & 100 \\
\hline $31-40$ & 36 & $0.17(0.07,0.32)$ & $1.63(1.29,2.04)$ & 0 & 23.3 & 20.4 & 10.7 & 45.6 \\
\hline $41-50$ & 19 & $0.26(0.10,0.51)$ & $2.81(1.64,4.04)$ & 7.1 & 3.1 & 47.7 & 28.7 & 6.5 \\
\hline $51-60$ & 12 & $0.41(0.17,0.72)$ & $1.87(0.75,3.12)$ & 0 & 77.8 & 15 & 0 & 7.2 \\
\hline $61-70$ & 12 & $0.17(0.02,0.48)$ & $3.58(2.24,4.88)$ & 13.6 & 11.6 & 43.2 & 26.8 & 0.4 \\
\hline$>70$ & 8 & $0(0,0.37)$ & $8.99(6.42,12.0)$ & 34.6 & 5.5 & 43.7 & 3.5 & 3.6 \\
\hline \multicolumn{9}{|l|}{ Stratum 1} \\
\hline$\leq 30$ & 4 & $0.25(0.01,0.81)$ & $0.50(0.08,1.12)$ & 0 & 0 & 0 & 0 & 100 \\
\hline $31-40$ & 3 & $0(0,0.71)$ & $3.79(2.01,6.67)$ & 0 & 0 & 0 & 100 & 0 \\
\hline $41-50$ & 16 & $0.5(0.27,0.75)$ & $1.78(0.86,2.83)$ & 0 & 0 & 0 & 100 & 0 \\
\hline $51-60$ & 11 & $0.27(0.07,0.61)$ & $2.57(1.12,4.25)$ & 0 & 0 & 0 & 99.9 & 0.1 \\
\hline $61-70$ & 5 & $0.2(0.01,0.72)$ & $2.49(0.68,4.44)$ & 0 & 0 & 0 & 100 & 0 \\
\hline$>70$ & 8 & $0.5(0.18,0.84)$ & $4.17(1.13,7.36)$ & 0 & 0 & 0 & 100 & 0 \\
\hline
\end{tabular}



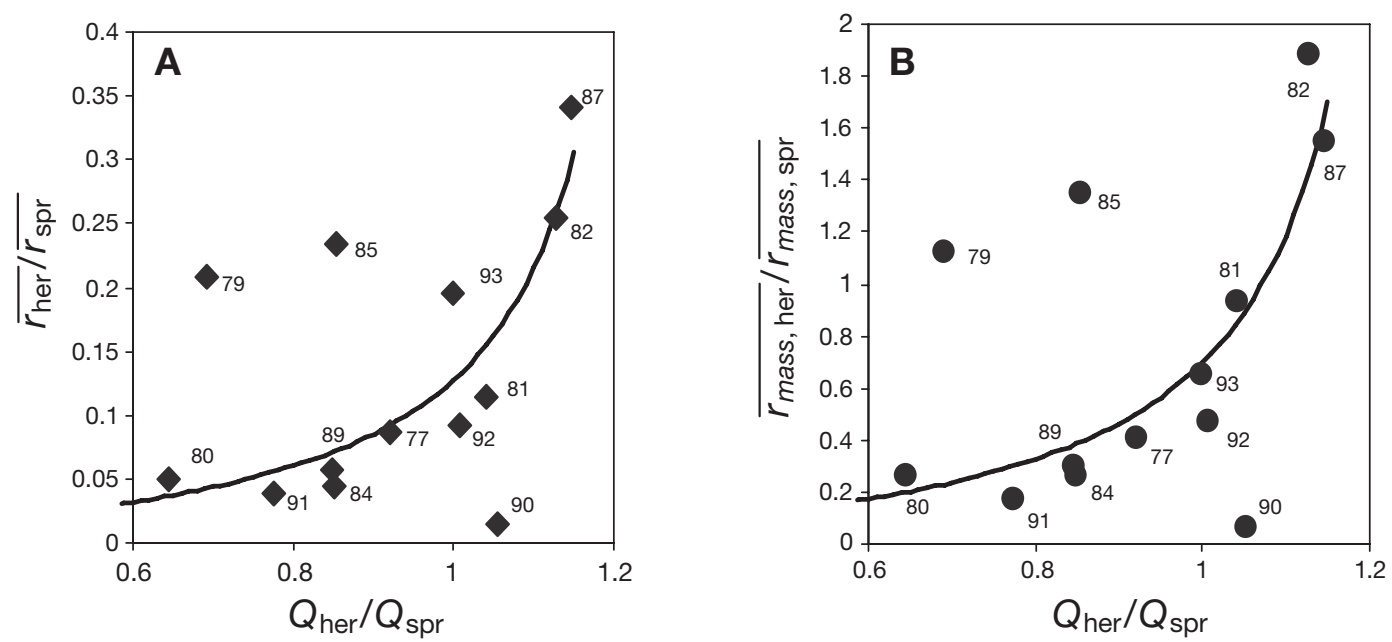

Fig. 8. (A) Average abundance of herring relative to average abundance of sprat $\left(\overline{r_{\text {her }}} / \overline{r_{\text {spr }}}\right)$ and (B) average mass of herring relative to average mass of sprat $\left(\overline{r_{\text {mass, her }}} / \overline{r_{\text {mass, spr }}}\right)$ in cod stomachs $\left(\mathrm{n}_{\text {tot }}=2589\right)$ versus fraction of the herring habitat occupied by cod divided by fraction of the sprat habitat occupied by $\operatorname{cod}\left(Q_{\mathrm{her}} / Q_{\mathrm{spr}}\right)$. Curves represent the model of aggregated functional response ratios (Eq. 7) with constant coefficients fitted to data. Numbers: sampling years, 1977 to 1993

model, we obtain $b_{H} / a_{H}=h_{2} f_{1}\left(\rho_{1}, 0\right)$, i.e. the average number of sprat consumed by a cod in Stratum 1 during a time interval that equals the average handling time of a herring. Fig. 8A reflects a situation of $b / a=27$. A cod cannot consume 27 sprat during the average handling time of 1 herring, unless handling time is unrealistically high, i.e. on the order of days or weeks rather than seconds. In the active response model with constant mass rate of per capita food consumption, we obtain $b / a=w_{\text {her }} / w_{\text {spr }}$ (Table 3 ), which may reflect the situation in Fig. $8 \mathrm{~B}$, where $b / a=5$, implying that a herring, on average, weighs 5 times as much as a sprat. As well as the equality of total consumption rates in Strata 1 and 2, this estimate of $b_{H} / a_{H}$ close to the body mass ratio of herring to sprat suggests that the concept of constancy in the average rate of total, per capita food consumption, represented by the active response model, is a reasonable assumption. The active re-

Table 3. Parameterisation of $a$ and $b$ in Eq. (6) according to the generalised Type 2 functional response model and to the active response model with a constant rate of food consumption by mass. The prey-specific parameters are preference measures $\left(\alpha_{i}\right)$, handling times $\left(h_{i}\right)$, average densities $\left(\rho_{i}\right)=$ $N_{i} / H_{i}$ and body weights $\left(w_{i}\right)$

\begin{tabular}{|ccc|}
\hline & Type 2 functional response & Active response model \\
\hline$a$ & $\frac{\alpha_{2}}{\alpha_{1}} \frac{\rho_{2}}{\rho_{1}} \frac{1}{1+\frac{\delta \alpha_{2} \rho_{2} h_{2}}{1+\delta \alpha_{1} \rho_{1} h_{1}}}$ & $\frac{\alpha_{2}}{\alpha_{1}} \frac{\rho_{2}}{\rho_{1}} \frac{1}{1+\frac{\alpha_{2} \rho_{2}}{\alpha_{1} \rho_{1}}} \frac{w_{1}}{w_{2}}$ \\
$b \quad \frac{\alpha_{2}}{\alpha_{1}} \frac{\rho_{2}}{\rho_{1}} \frac{h_{2}}{h_{1}} \frac{1}{1+\frac{1+\delta \alpha_{2} \rho_{2} h_{2}}{\delta \alpha_{1} \rho_{1} h_{1}}}$ & $\frac{\alpha_{2}}{\alpha_{1}} \frac{\rho_{2}}{\rho_{1}} \frac{1}{1+\frac{\alpha_{2} \rho_{2}}{\alpha_{1} \rho_{1}}}$ \\
\hline
\end{tabular}

sponse model was therefore used to demonstrate the population consequences of the relationship between overlap and diet.

For the active response model, Fig. 9 shows the effect of the prey abundance ratio on the ratio of prey in the diet of cod, at different overlap ratios. The ratio of herring to sprat in the cod diet will increase at rate $A\left(H_{\mathrm{spr}} / H_{\text {her }}\right)\left(O_{\text {her }} / O_{\text {spr }}\right)$, if the abundance ratio increases in situations of low herring abundance compared to sprat. At the other extreme, when $N_{\text {her }} / N_{\text {spr }}$ is large, the maximum ratio of herring to sprat in the aggregate cod diet becomes $(A / B)\left[O_{\text {her }} / O_{\text {spr }} /(1-\right.$ $\left.\left.O_{\text {her }} / O_{\text {spr }}\right)\right]$. Both increase rate and maximum ratio of

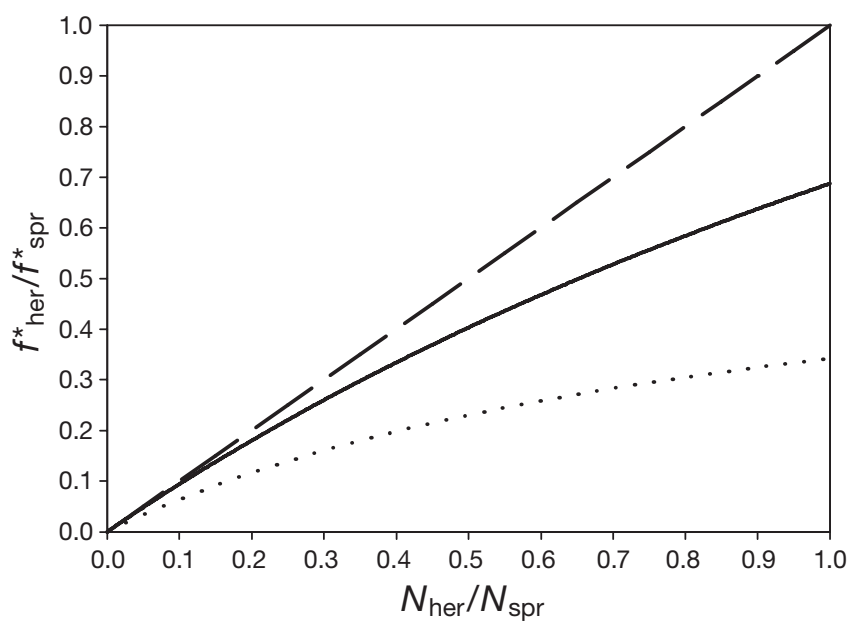

Fig. 9. Aggregated (i.e. averaged to population level) per capita consumption rate by cod of herring relative to sprat $\left(f^{*}{ }_{\text {her }} / f^{*}{ }_{\text {spr }}\right)$ in relation to the relative abundance of the 2 prey types $\left(N_{\text {her }} / N_{\mathrm{spr}}\right)$, as predicted by the active response model. Curves represent the relationship at different ratios of cod-herring to cod-sprat overlaps $\left(O_{\text {her }} / O_{\text {spr }}=1\right.$ [dashed], 0.7 [solid], 0.4 [dotted]) 
herring to sprat decrease when overlap ratios decline during stagnation periods. In Fig. 9 the prey habitat size ratio is modelled as a function of the overlap ratio by the linear relationship mentioned above, i.e. $H_{\text {spr }} / H_{\text {her }}=1.29\left(1-O_{\text {her }} / O_{\text {spr }}\right)+1$. This correlation between overlap and habitat ratios implies that in the active response model the overlap-specific characteristics of the aggregated response ratio (Eq. 13) depend exclusively on the preference ratio $\alpha_{\text {her }} / \alpha_{\text {spr }}$.

\section{DISCUSSION}

We showed that intrusions of oxygenated and highly saline water from the North Sea regulate the habitat volumes of Atlantic cod Gadus morhua in the Bornholm basin and its main prey species herring Clupea harengus and sprat Sprattus sprattus, as well as their vertical overlaps. We further demonstrated the effect of these environmentally driven changes in habitat overlaps on the aggregate diet of the cod population.

\section{Habitat thresholds}

The $50.6 \%$ oxygen limit for herring $\left(d_{50}\right)$ was surprisingly high compared to literature values of ca. $20 \%$ (Hognestad 1994, Neuenfeldt \& Beyer 2003). In laboratory experiments, however, Atlantic herring exhibit deviations from hormonal (corticosteroid), metabolic (glucose) and ionoregulatory (osmolality) homeostasis of between 60 and $40 \%$ saturation (N. A. Herbert \& J. F. Steffensen unpubl. data, Marine Biological Laboratory, Helsingør, Denmark). This indicates that herring can cope with oxygen saturation as low as ca. $20 \%$, but probably do so only if necessary.

The $p_{\text {c }}$ estimate of $10.5 \%$ for cod was in line with literature values (Schurmann \& Steffensen 1992, Claireaux et al. 1995). Although, for example, Plante et al. (1998) pointed out that in their experiment $50 \%$ of the Atlantic cod died when kept $>96$ h at $28 \%$ saturation, Atlantic cod in tank experiments undertook short excursions ( $\leq 2 \mathrm{~min}$ ) into $16 \%$ oxygen saturation if food was offered (Claireaux et al. 1995).

The $p_{\mathrm{c}}$ estimate of $16.9 \%$ for sprat was also in line with literature values (Neuenfeldt \& Beyer 2003), and corresponds to the vertical distribution of sprat eggs in March (Köster \& Möllmann 2000).

\section{Habitat volumes and PEV}

The dynamics of habitat volumes and overlaps are determined by vertical variations in oxygen saturation (Fig. 5) and by changes in the vertical position of the halocline. These vertical variations are caused by variation in the annual inflow of oxygen-rich and high-saline deep water from the North Sea (Figs. 6 \& 7 ). Compared to changes in the depth of the oxygen threshold, changes in the vertical position of the halocline have a greater effect on habitat volumes, due to the conical geometry of the basin. This is because the halocline always occurs at a shallower depth than the oxygen threshold. It is, however, the magnitude of the relative changes that determines overlap dynamics. For example, changing the salinity threshold for the upper vertical limit of the habitat volume of cod from 9 to $10 \mathrm{psu}$, or extending the additional free range for herring and sprat from 10 to $20 \mathrm{~m}$ did not affect the results displayed in Fig. 8.

\section{Cod diet}

The aggregate cod diet in the Baltic changes as a function of inflow dynamics. In the Gotland basin of the Baltic Sea, cod $>30 \mathrm{~cm}$ captured mostly sprat at depths $>70 \mathrm{~m}$, but relatively more herring at depths $<70 \mathrm{~m}$ (Uzars 1994), in agreement with our results.

The models fitted to the stomach data in Fig. 8 did not account for changes in the coefficients $a$ and $b$ (Table 3) caused by changes in the abundance and weight ratios of herring to sprat from 1977 to 1993. We consider this simplification justifiable for several reasons. First, we believe that the major impact of changes in average prey densities due to changes in their habitat volumes has been accounted for by replacing the overlap ratio with the less variable occupation ratio. Second, the herring population has not changed drastically during the period (Köster et al. 2001), so relatively small changes in herring abundance in the basin are likely to show up in Fig. 8 in a nonpredictable way as noise. Third, excluding the data from 1989 onwards, which meant excluding both the sprat abundance outburst (Köster et al. 2001) and a $50 \%$ increase in the weight ratio $w_{\text {spr }} / w_{\text {her, }}$ did not change the parameter estimates significantly.

Three data points are outside the 95\% confidence limits of the model prediction. The 1979 and 1990 data points, with only 47 and 71 sampled stomachs, are probably less representative for cod feeding than other years. However, the 1985 data point is of importance since it represents 380 stomachs with an extraordinarily large fraction of herring. Neither extreme hydrographic conditions nor exceptional abundances of herring or sprat, compared to adjacent years, potentially explain this extreme observation. Possibly, stomach sampling was not horizontally representative due to small-scale heterogeneity. Unfortunately, positional information is not available on the present aggregation 
level of the stomach data. Therefore, this aspect cannot be investigated further at present. We do not consider the presence of these 3 data points critical for our analysis, because excluding them would not change the parameter estimates, but it would increase $\mathrm{r}^{2}$ to ca. 0.9 .

\section{Population consequences}

The explicit incorporation of spatial overlap in predator-prey dynamics can aid in understanding observed changes in the ecosystem. A major change in the Baltic Sea ecosystem and also in the Bornholm basin (Köster et al. 2001) was the drastic increase in sprat abundance during the late 1980s. Using standard multispecies assessment methodology, the herring to sprat abundance ratio decreased from ca. 0.9 in the early 1980 s to ca. 0.15 in the early 1990 s, due to the increase in sprat (Köster et al. 2001). The overlap ratio during the 1980s ranged between 0.4 and 0.85 , with an average around 0.7 . Considering for simplicity only this average overlap ratio of $0.7, \operatorname{cod}$ consumption of sprat was on a higher level than would be expected if herring and sprat had been sharing the same (potential encounter) volume (solid vs. dashed line in Fig. 9). The predation on sprat decreased with the reduced cod stock in the 1980s and consequently lowered the abundance ratio of herring to sprat, since the herring stock can be considered constant in this context. At a decreasing abundance ratio of herring to sprat, the consumption ratio will decrease more slowly than the decreasing abundance ratio. This means that the percentage of the sprat stock consumed by cod will actually decrease compared to that of herring. Thus, the environmentally driven overlap will amplify the emergence of an increase in the sprat stock, in particular when major inflows do not occur.

Environmentally driven overlaps may therefore play an important role in Baltic regime shifts. However, this study only represents the first investigation of how the clupeid diet of adult cod depends on the hydrographic conditions in the Bornholm basin during March. A thorough examination of the environmental impact on the sprat increase requires an understanding of migration and feeding behaviour of cod, herring and sprat, together with a quantification of their spatial overlap dynamics in all seasons. Furthermore, any future stomach sampling should representatively sample the different regions of the cod habitat.

If predator-prey overlaps are disregarded, then the observed diet stability can be misinterpreted as a situation of increasing preference by the individual predator for a prey that decreases in abundance. Such a situation is referred to as negative switching (Chesson 1984), which usually is quantified by an empirical power relationship (Elton \& Greenwod 1976). Instead, using conceptual modelling, we derived from first principles the somewhat less accelerating Monod type of functional form for the ratio in the diet vs. the ratio in the environment (Fig. 9). Thereby, we showed that, if one part of the predator habitat contains both prey types and another region contains only one of them, then 'apparent' negative switching can be observed. 'Apparent' means that negative switching will emerge at the population level although it does not occur at the individual level.

The present results have bearings on ecosystem dynamics in general, as situations of overlap differences between prey types are likely to occur at various spatial scales. Overlap situations can also comprise horizontal determinants, such as substrate quality and proximity to hydrographic fronts. Our approach showed that mechanistic models are useful for the examination of the population consequences of predator-prey overlaps, and for elucidating the impacts of environmental and climatic changes.

Acknowledgements. We thank R. Nielsen for the kind permission to use the December 1998 data, J. Tomkiewicz for making 1998/1999 survey data available, and ICES for making the stomach data available. We furthermore thank K. Kristensen and U. Thygesen for helping with the statistical programming, and O. Bagge, F. W. Köster, C. Möllmann, K. H. Andersen, N. G. Andersen, B. MacKenzie, K. Hüssy, M. Horsten and 4 anonymous reviewers for valuable comments. We also thank the officers, crew and scientific staff on board RV 'Dana' for their valuable work at sea. The present work was part of 2 projects entitled 'Development of improved models of fisheries impact on marine fish stocks and ecosystems' and 'Development of spatially explicit management tools (SPEX I)'; both were supported by the Danish Ministry of Food, Agriculture and Fisheries, and were carried out in collaboration with the Baltic STORE (FAIR 98 3959) and BECAUSE (SSP8-CT-2003-502482) projects, with financial support from the European Commission.

\section{LITERATURE CITED}

Andersen NG (2001) A gastric evacuation model for three predatory gadoids and implications of using pooled field data of stomach contents to estimate food rations. J Fish Biol 59:1198-1217

Chesson J (1978) Measuring preference in selective predation. Ecology 59:211-215

Chesson PL (1984) Variable predators and switching behaviour. Theor Popul Biol 26:1-26

Claireaux G, Webber DM, Kerr SR, Boutilier RG (1995) Physiology and behaviour of free-swimming Atlantic cod (Gadus morhua) facing fluctuating salinity and oxygen conditions. J Exp Biol 198:61-69

Efron B (1993) An introduction to the bootstrap. Monographs on statistics and applied probability 57. Chapman \& Hall, London

Elton RA, Greenwood JJD (1976) Exploring apostatic selection. Heredity 25:629-633

Fretwell SD, Lucas HL Jr (1970) On territorial behaviour and 
other factors influencing habitat distribution in birds. I. Theoretical development. Acta Biotheor 19:16-36

Gibson RN (1994) Impact of habitat quality and quantity on the recruitment of juvenile flatfish. Neth J Sea Res 32(2): 191-206

Harden-Jones FR, Scholes P (1985) Gas secretion and resorption in the swimbladder of cod Gadus morhua. J Comp Physiol B 155:319-331

Hognestad PT (1994) The Lake Rossfjord herring (Clupea harengus L.) and its environment. ICES J Mar Sci 51: 281-292

Holling CS (1959) The components of predation as revealed by a study of small mammal predation of the European pine sawfly. Can Entomol 91:293-320

ICES (International Council for the Exploration of the Sea) (1999) Report of the study group on multispecies model implementation in the Baltic. ICES CM H:5 (mimeo)

ICES (International Council for the Exploration of the Sea) (2004) Report of the study group on closed spawning areas of eastern Baltic cod. ICES CM/ACFM:17 (mimeo)

Johansen GO, Bogstad B, Mehl S, Ulltang Ø (2004) Consumption of juvenile herring (Clupea harengus) by cod (Gadus morhua) in the Barents Sea: a new approach to estimating consumption in piscivorous fish. Can J Fish Aquat Sci 61: 343-359

Köster FW, Möllmann C (2000) Egg cannibalism in Baltic sprat Sprattus sprattus. Mar Ecol Prog Ser 196:269-277

Köster FW, Möllmann C, Neuenfeldt S, St. John M, Pliksh M, Voss R (2001) Developing Baltic cod recruitment models. I. Resolving spatial and temporal dynamics of spawning stock and recruitment for cod, herring and sprat. Can J Fish Aquat Sci 58:1516-1533

MacKenzie BR, Hinrichsen HH, Plikshs M, Wieland K, Zezera AS (2000) Quantifying environmental heterogeneity: habitat size necessary for successful development of cod

Editorial responsibility: Otto Kinne (Editor-in-Chief), Oldendorf/Luhe, Germany
Gadus morhua eggs in the Baltic Sea. Mar Ecol Prog Ser 193:143-156

Murdoch WW (1973) The functional response of predators. J Appl Ecol 10:335-342

Neuenfeldt S (2002) The influence of oxygen saturation on the distributional overlap of predator (cod, Gadus morhua) and prey (herring, Clupea harengus) in the Bornholm Basin of the Baltic Sea. Fish Oceanogr 11:11-17

Neuenfeldt S, Beyer JE (2003) Oxygen and salinity characteristics of predator-prey distributional overlaps shown by predatory Baltic cod during spawning. J Fish Biol 62: 168-183

Nilsson F, Thygesen UH, Lundgren B, Nielsen BF, Nielsen JR, Beyer JE (2002) Modeling the dispersive migration of sprat, Sprattus sprattus, and herring, Clupea harengus, at dusk in the Baltic Sea. ICES Mar Sci Symp 128:923-946

Parmanne R, Rechlin O, Sjöstrand B (1994) Status and future of herring and sprat stocks in the Baltic Sea. Dana 10: $29-60$

Plante S, Chabot D, Dutil JD (1998) Hypoxia tolerance in Atlantic cod. J Fish Biol 53:1342-1356

Schinke H, Matthäus W (1998) On the causes of major Baltic inflows - an analysis of long time series. Cont Shelf Res 18:67-97

Schurmann H, Steffensen JF (1992) Lethal oxygen levels at different temperatures and the preferred temperature during hypoxia of the Atlantic cod, Gadus morhua L. J Fish Biol 41:927-934

Seifert T, Kayser B (1995) A high resolution spherical grid topography of the Baltic Sea. Meereswissenschaftliche Berichte/Marine Science Reports 9, Institut für Ostseeforschung, Warnemünde

Uzars D (1994) Feeding of cod (Gadus morhua callarias L.) in the Central Baltic in relation to environmental changes. ICES Mar Sci Symp 198:612-623

Submitted: February 9, 2002; Accepted: October 23, 2005

Proofs received from author(s): March 2, 2006 